\title{
Procedure for Estimation of Additive Time Series Model
}

\author{
K.C.N. Dozie ${ }^{1}$, M.U. Uwaezuoke ${ }^{2}$ \\ ${ }^{I}$ Department of Statistics Imo State University, Owerri, Imo State, Nigeria \\ ${ }^{2}$ Department of Mathematics Imo State University, Owerri, Imo State, Nigeria
}

\begin{abstract}
The procedure for estimation of lineartrend cycle and seasonal components and accepts additive model is examined in this study. Estimates of the periodic, seasonal and overall means and variances with error terms and error variances are obtained for additive model. Empirical example based on short series in which trend cycle component is jointly estimated for the linear case is applied to determine suitable model for decomposition of the study series.
\end{abstract}

Keywords: Descriptive Time Series, Additive Model, Error Term, Buys-Ballot Estimate, Error Variance, Suitable Model.

\section{INTRODUCTION}

$\mathrm{D}$ escriptive method involves the assessment of trend, seasonality, cycles, changes in level, turning points and so on that may influence the series. The reason of time series decomposition method is to separate the time series components available in the series. The components are; i) the trend component ii) the seasonal component iii) the cyclical component iv) the irregular component. The trend and cyclical component could be estimated to obtain the trend-cycle component in short time period [1].Therefore, the decomposition models are

Additive Model:

$$
\mathrm{X}_{\mathrm{t}}=\mathrm{M}_{\mathrm{t}}+\mathrm{S}_{\mathrm{t}}+\mathrm{e}_{\mathrm{t}}
$$

Multiplicative Model:

$$
X_{t}=M_{t} \times S_{t} \times e_{t}
$$

and Mixed Model

$$
X_{t}=M_{t} \times S_{t}+e_{t} .
$$

On when to use each of the additive, multiplicative and mixed models, Chatfield [1] observed that, the seasonal indices stays roughly the same size, regardless of the mean level, then it is said to be additive model and shown in equation (1) may be applied.

Iwueze and Nwogu [2] noted that, the seasonal variances of the Buys-Ballot table are constant for the additive model, but contains the seasonal effect for the multiplicative model. In addition, in obtaining linear trend cycle and seasonal components with regards to the periodic, seasonal and overall means and variances of additive and multiplicative models Iwueze and Nwogu [2]ignored the error component and assumed that every observation in time series data is available. In order words, they made no provision for error term. We consider the periodic, seasonal and overall means and variances with error terms and error variances, when arranged in Buys-Ballot table (see section 2.1).

\section{METHODOLOGY}

This research adopted Buys-Ballot methodfor time series decomposition. For details of Buys-Ballot method see Wei [3], Iwueze and Nwogu [2], Nwogu, et al, [4],Dozie [5], Dozie and Uwaezuoke [6].

Table 1: Buys - Ballot Tabular Arrangement of Time Series Data

\begin{tabular}{|c|c|c|c|c|c|c|c|c|c|}
\hline \multirow{2}{*}{ Rows (i) } & \multicolumn{9}{|c|}{ Columns j } \\
\cline { 2 - 10 } & 1 & 2 & $\cdots$ & $j$ & $\cdots$ & $s$ & $T_{i .}$ & $\bar{X}_{i .}$ & \multicolumn{1}{c|}{$\hat{\sigma}_{i .}$} \\
\hline 1 & $X_{1}$ & $X_{2}$ & $\cdots$ & $X_{j}$ & $\cdots$ & $X_{s}$ & $T_{1 .}$ & $\bar{X}_{1 .}$ & $\hat{\sigma}_{1}$ \\
\hline 2 & $X_{s+1}$ & $X_{s+2}$ & $\cdots$ & $X_{s+j}$ & $\cdots$ & $X_{2 s}$ & $T_{2 .}$ & $\bar{X}_{2 .}$ & $\hat{\sigma}_{2}$ \\
\hline 3 & $X_{2 s+1}$ & $X_{2 s+2}$ & $\cdots$ & $X_{2 s+j}$ & $\cdots$ & $X_{3 s}$ & $T_{3 .}$ & $\bar{X}_{3 .}$ & $\hat{\sigma}_{3}$ \\
\hline$\vdots$ & $\vdots$ & $\vdots$ & $\vdots$ & $\vdots$ & $\vdots$ & $\vdots$ & $\vdots$ & $\vdots$ & $\vdots$ \\
\hline$i$ & $X_{(i-1) s+1}$ & $X_{(i-1) s+2}$ & $\cdots$ & $X_{(i-1) s+j}$ & $\cdots$ & $X_{i s}$ & $T_{i .}$ & $\bar{X}_{i .}$ & $\hat{\sigma}_{i .}$ \\
\hline$\vdots$ & $\vdots$ & $\vdots$ & $\vdots$ & $\vdots$ & $\vdots$ & $\vdots$ & $\vdots$ & $\vdots$ & $\vdots$ \\
\hline$m$ & $X_{(m-1) s+1}$ & $X_{(m-1) s+2}$ & $\cdots$ & $X_{(m-1) s+j}$ & $\cdots$ & $X_{m s}$ & $T_{m .}$ & $\bar{X}_{m .}$ & $\hat{\sigma}_{m .}$. \\
\hline$T_{. j}$ & $T_{.1}$ & $T_{.2}$ & $\cdots$ & $T_{. j}$ & $\cdots$ & $T_{s}$ & $T_{. .}$ & & \\
\hline $\bar{X}_{. j}$ & $\bar{X}_{.1}$ & $\bar{X}_{.2}$ & $\cdots$ & $\bar{X}_{. j}$ & $\cdots$ & $\bar{X}_{. s}$ & & $\bar{X}_{. .}$ & \\
\hline$\hat{\sigma}_{. j}$ & $\hat{\sigma}_{.1}$ & $\hat{\sigma}_{.2}$ & $\cdots$ & $\hat{\sigma}_{. j}$ & $\cdots$ & $\hat{\sigma}_{. s}$ & & & $\hat{\sigma}_{x}$ \\
\hline
\end{tabular}

Where, $\mathrm{m}=$ number of periods, $\mathrm{s}=$ length of periodic interval and $\mathrm{n}=$ length of the series 
2.1 Derivation of the periodic, seasonal and overall means and variances with error terms and error variances of the Buys-Ballot

Table when trend cycle component is linear

For Additive Model

$X_{t}=M_{t}+S_{t}+e_{t}$

Where $M_{t}$ is the trend-cycle component, $S_{t}$ is the seasonal indices and $e_{t}$ is the error. The assumption is that, the error term $e_{t}$ is the Gaussian white noise $N\left(0, \sigma_{1}^{2}\right)$ and sum of the seasonal indices over a complete period is zero $\left(\sum_{j=1}^{S} S_{j}=0\right)$

For a series that has linear trend, when arranged in a BuysBallot table with m-rows and s- columns; $t=(i-1) s+j, \quad i=1,2, \ldots, m, \quad j=1,2, \ldots, s$

$X_{(i-1) s+j}=M_{(i-1) s+j}+S_{(i-1) s+j}+e_{(i-1) s+j}$

$X_{i j}=M_{(i-1) s+j}+S_{j}+e_{(i-1) s+j}$

Without loss of generality, let

$$
\begin{aligned}
& X_{i j}=X_{(i-1) s+j}, \quad M_{i j}=M_{(i-1) s+j}, e_{i j}=e_{(i-1) s+j} \\
& M_{(i-1) s+j}=a+b[(i-1) s+j]
\end{aligned}
$$

When trend cycle is linear,

$$
\begin{aligned}
& X_{i j}=M_{i j}+S_{j}+e_{i j} \\
& \bar{X}_{i .}=\frac{1}{s} \sum_{j=1}^{s} X_{i j}, \quad=\frac{1}{s} \sum_{j=1}^{s} M_{i j}+S_{j}+\bar{e}_{i .}
\end{aligned}
$$

For linear trend

$$
\begin{aligned}
& M_{i j}=a+b[(i-1) s+j] \\
& \frac{1}{s} \sum_{j=1}^{s} M_{i j}+S_{j}=\frac{1}{s} \sum_{j=1}^{s}\left\{a+b[(i-1) s+j]+S_{j}\right\}
\end{aligned}
$$

$$
\bar{X}_{i .}=\frac{1}{s} \sum_{j=1}^{s}\left\{a+b s(i-1)+b j+S_{j}\right\}+\bar{e}_{. j}
$$

Therefore, the periodic average is

$$
=a-b\left(\frac{s-1}{2}\right)+(b s) i+e_{i .}
$$

The seasonal average of the Buys-Ballot table is derived as

$$
\begin{aligned}
& X_{i j}=M_{i j}+S_{j}+e_{i j} \\
& \bar{X}_{. j}=\frac{1}{m} \sum_{i-1}^{m} X_{i j} \\
& =\frac{1}{m} \sum_{i=1}^{m} M_{i j}+S_{j}+e_{. j}^{-}
\end{aligned}
$$

For linear trend

$$
\begin{aligned}
& M_{i j}=a+b[(i-1) s+j] \\
& \frac{1}{m}\left(\sum_{i=1}^{m} M_{i j}+S_{j}\right)=\frac{1}{m} \sum_{i=1}^{m}\left\{a+b[(i-1) s+j]+S_{j}\right\}
\end{aligned}
$$

$\bar{X}_{. j}=a+\frac{b s}{m} \sum_{i=1}^{m}(i-1)+b j+S_{j}+\bar{e}_{. j}$

Therefore, the seasonal average is

$$
=a+b\left(\frac{n-s}{2}\right)+b j+S_{j}+e_{. j}^{-}
$$

The overall average of the observation is obtained as

$$
\begin{aligned}
& \bar{X}_{. .}=\frac{1}{m} \sum_{i=1}^{m} \bar{X}_{i .}(15) \\
& =\frac{1}{m} \sum_{i=1}^{m}\left\{a-b\left(\frac{s-1}{2}\right)+(b s) i+\bar{e}_{i .}\right\}
\end{aligned}
$$

Therefore, the overall average is

$$
=a+b\left(\frac{n+1}{2}\right)+e^{-}
$$


Table 2: Estimates of Periodic, Seasonal and Overall Means

\begin{tabular}{|c|c|}
\hline \multirow{2}{*}{ Measures } & Linear trend $\mathrm{M}_{\mathrm{t}}=\mathrm{a}+\mathrm{b}_{\mathrm{t}}, \mathrm{t}=1,2, \ldots, \mathrm{n}=\mathrm{ms}$ \\
\cline { 2 - 3 } $\bar{X}_{i .}$ & $a+b\left(\frac{s-1}{2}\right)+(b s) i+e_{i .}^{-}$ \\
\hline $\bar{X}_{. j}$ & $a+\frac{b}{2}(n-s)+b j+s_{j}+e_{. j}^{-}$ \\
\hline $\bar{X}_{. .}$ & $a+b\left(\frac{n+1}{2}\right)+\bar{e}_{. .}$ \\
\hline
\end{tabular}

As given in Table 2, the impressive observation from is that, the seasonal means with error term contain both the trending curves of the original series and seasonal indices.

The periodic variance of the observation is given as

$$
\begin{aligned}
& \hat{\sigma_{i .}^{2}}=\frac{1}{s-1} \sum_{j=1}^{s}\left(X_{i j}-\bar{X}_{i .}\right)^{2} \\
& (s-1) \hat{\sigma}_{i .}^{2}=\sum_{j=1}^{s}\left(M_{i j}+S_{j}+e_{i j}-\frac{1}{s} \sum_{j=1}^{s} M_{i j}-e_{i .}\right)^{2} \\
& M_{i j}=a+b[(i-1) s+j] \\
& =\sum_{j=1}^{s}\left\{\begin{array}{c}
a+b[(i-1) s+j]-\left(a+b\left(\frac{s-1}{2}\right)+(b s) i+e_{i}\right) \\
=-b\left(\frac{s-1}{2}\right)+b_{j}+S_{j}+\left(e_{i j}-e_{i .}\right)
\end{array}\right.
\end{aligned}
$$

Hence, periodic variance is

$$
=b^{2} s\left(\frac{s+1}{2}\right)+\frac{2 b}{s-1} \sum_{j=1}^{s} j S_{j}+\frac{1}{s-1} \sum_{j=1}^{s} S_{j}^{2}+\sigma_{1}^{2}
$$

For the seasonal variance, we obtain;

$$
\hat{\sigma}_{. j}^{2}=\frac{1}{m-1} \sum_{i=1}^{m}\left(X_{i j}-\bar{X}_{. j}\right)^{2}
$$

$=\frac{1}{m-1} \sum_{i=1}^{m}\left\{[a+b s(i-1)+b j]+S_{j}+e_{i j}-\left(a+b\left(\frac{n-s}{2}\right)+b j+S_{j}+e_{. j}^{-}\right)\right\}^{2}$

$$
=\frac{1}{m-1} \sum_{i=1}^{m}\left\{\left(a+b s(i-1)-a-b\left(\frac{n-s}{2}\right)\right)+\left(e_{i j}-e_{. j}^{-}\right)\right\}^{2}
$$

Thus, the seasonal variance is

$$
=\frac{b^{2} n(n+s)}{12}+\sigma_{1}^{2}
$$

The overall variance of the Buys-Ballot table is derived as

$$
\hat{\sigma}_{x}^{2}=\frac{1}{n-1} \sum_{i=1}^{m} \sum_{j=1}^{s}\left(X_{i j}-\bar{X}_{. .}\right)^{2}
$$

$$
=\frac{1}{n-1} \sum_{i=1}^{m} \sum_{j=1}^{s}\left\{\left[a+b s(i-1)+b_{j}\right]+S_{j}+e_{i j}-a-\frac{b s(m-1)}{2}-\frac{b}{s} \sum_{j=1}^{s} j S_{j}-\bar{e}\right\}^{2}
$$

$(n-1) \hat{\sigma}_{x}^{2}=\sum_{i=1}^{m} \sum_{j=1}^{s}\left\{b s(i-1)+b_{j}+S_{j}-\frac{b s(m-1)}{2}-\frac{b}{s} \sum_{j=1}^{s} j S_{j}+e_{i j}-e_{.}^{-}\right\}^{2}$

Finally, the overall variance is

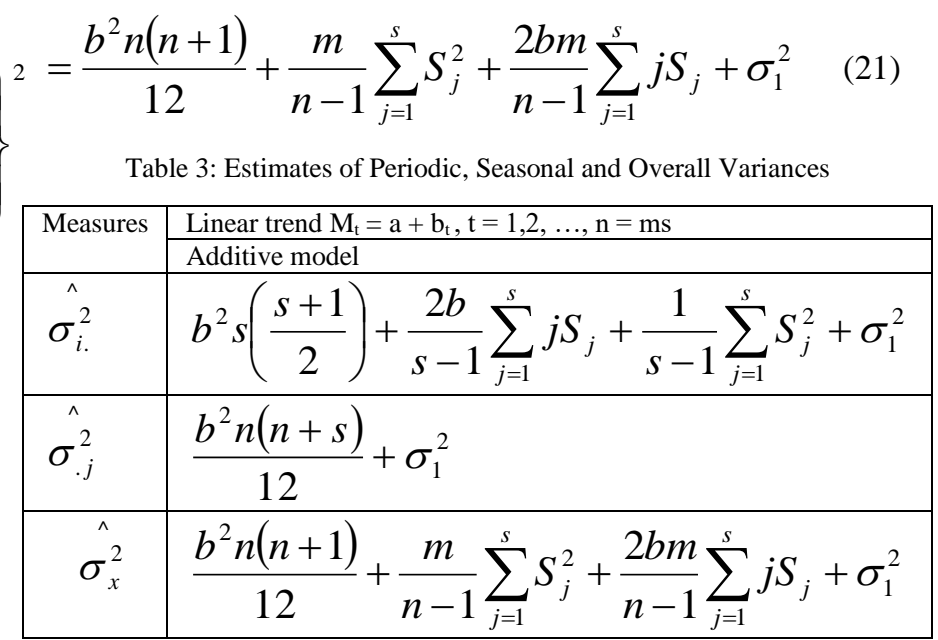

As shown in Table 3, observe that, the seasonal variance contain the trending series and seasonal indices

\subsection{Tests for Constant Variance}

Levene's test statistic for the null hypothesis

$H_{0}: \sigma_{1}^{2}=\sigma_{2}^{2}=\ldots=\sigma_{k}^{2}$

Against the alternative

$$
H_{1}: \sigma_{1}^{2} \neq \sigma_{j}^{2} \text { for at least one pair }(i j)
$$


is defined as

$$
W=\frac{(N-K)}{K-1} \frac{\sum_{j=1}^{K} N_{i}\left(Z_{\square j}-Z_{\square}\right)^{2}}{\sum_{i=1}^{K} \sum_{j=1}^{N}\left(Z_{i j}-Z_{\square j}\right)^{2}}
$$

Where, $\mathrm{K}$ is the number of different groups to which the sampled cases belong, $N i$ is the number of cases in the $\mathrm{j}^{\text {th }}$ group, $N$ is total number of cases in all groups, while $Y_{i}$ is the value of the measured variable for the $\mathrm{j}^{\text {th }}$ case from the group.

$Z_{i j}=\left|\begin{array}{c}Y_{i j}-\bar{Y}_{i} \\ Y_{i j}-\hat{Y}_{i}\end{array}\right|$

$\bar{Y}_{i .}$ is a mean of the $i^{\text {th }}$ group.

$\hat{Y}_{i}$ is a median of the $i^{\text {th }}$ group

$Z_{i}=\frac{1}{N i} \sum_{j=1}^{N_{i}} Z_{i j}$ Is the mean of the $Z_{i j}$ for group i.

$Z_{\square}=\frac{1}{N} \sum_{i=1}^{K} \sum_{j=1}^{N_{j}} Z_{i j}$ Is the mean of all $Z_{i j}$

The test statistic $\mathrm{W}$ is approximately as F-distribution with $k-$ $I$ and $\mathrm{N}-\mathrm{k}$ degrees of freedom. The Levene's test statistic is re-written to suit the Buys-Ballot method. Where $N=m s, k=s, N_{i}=m$, the statistic in (22) is given as

$$
\begin{aligned}
& W=\frac{(m s-S)}{s-1}\left|\frac{\sum_{j=1}^{S} m\left(Z_{\square j}-Z_{\square}\right)^{2}}{\sum_{i=1}^{m} \sum_{j=1}^{s}\left(Z_{i j}-Z_{\square j}\right)}\right| \\
& W=\frac{S(m-1) m}{S-1} \sum_{j=1}^{S} m\left(Z_{\square j}-Z_{\square}\right)^{2} \\
& Z_{i j}^{m} \sum_{j=1}^{s}\left(Z_{i j}-Z_{\square j}\right) \\
& y_{i \square}=\left|y_{i j}-y_{i \square}\right|(28) \\
& Z_{\square j}=\frac{1}{m} \sum_{i=1}^{m} Z_{i j}(29) \\
& Z_{\square}=\frac{1}{s} \sum_{j=1}^{s} Z_{\square j} \text { (30) }
\end{aligned}
$$

\section{REAL LIFE EXAMPLE}

Table 4 indicates the data on monthly road traffic offences in Nigeria from January 2006 to December, 2017. The graphs of the data which was collected by the Federal Road Safety Corp (FRSC), Nigeria are shown in Figures 3.1 and 3.2. As Figures 3.1 and 3.2 and Table 3 show, the series is seasonal with no

\begin{tabular}{|c|c|c|c|c|c|c|c|c|c|c|c|c|c|c|}
\hline Year & Jan. & Feb. & Mar. & Apr. & May & Jun. & Jul. & Aug. & Sept. & Oct. & Nov. & Dec. & $\bar{X}_{i}$ & $\sigma_{i}^{2}$ \\
\hline 2007 & 27905 & 32732 & 42104 & 31288 & 40529 & 30727 & 42742 & 43807 & 41146 & 38152 & 121049 & 47113 & 44941.2 & $\begin{array}{c}610818258 . \\
7 \\
\end{array}$ \\
\hline 2008 & 26613 & 35623 & 36655 & 41333 & 36827 & 26714 & 24782 & 83102 & 21793 & 26793 & 25334 & 31170 & 34728.3 & 268434131 \\
\hline 2009 & 38268 & 47134 & 30474 & 34365 & 31714 & 30673 & 31584 & 34008 & 36479 & 43294 & 40956 & 36710 & 36304.9 & 28174340.8 \\
\hline 2010 & 41683 & 46299 & 59036 & 58401 & 55681 & 52653 & 52107 & 56362 & 43392 & 47885 & 39863 & 36878 & 49186.7 & $\begin{array}{c}57679005.3 \\
3 \\
\end{array}$ \\
\hline 2011 & 36223 & 45036 & 50404 & 35008 & 55690 & 50946 & 55095 & 56681 & 59273 & 62365 & 53103 & 40482 & 50025.5 & 80211908.3 \\
\hline 2012 & 39294 & 50635 & 84203 & 35797 & 46285 & 43715 & 50989 & 49011 & 42607 & 37393 & 57381 & 42619 & 48327.4 & $\begin{array}{c}166439233 . \\
7\end{array}$ \\
\hline 2013 & 44724 & 39486 & 38661 & 58112 & 52004 & 48191 & 36777 & 31262 & 43449 & 51205 & 49543 & 56472 & 45823.8 & 67562322.7 \\
\hline 2014 & 42376 & 49697 & 43837 & 44665 & 49674 & 48038 & 50812 & 56405 & 52633 & 45569 & 51234 & 41617 & 48046.4 & 20260646.3 \\
\hline 2015 & 32164 & 38125 & 36687 & 29488 & 30114 & 25486 & 27264 & 30927 & 26211 & 25224 & 26201 & 24772 & 29388.6 & 19895997.2 \\
\hline 2016 & 23421 & 22098 & 23519 & 23348 & 21468 & 21871 & 19224 & 17262 & 20173 & 15726 & 17288 & 16709 & 20175.6 & 8142224.6 \\
\hline 2017 & 12009 & 9692 & 13609 & 10729 & 10584 & 9582 & 11242 & 8986 & 7943 & 9066 & 8139 & 7328 & 9909.1 & 3307375.2 \\
\hline
\end{tabular}
evidence of upward trend or downward trend. There is an upsurge of the series in March, August and November and a drop in January and December. The yearly and seasonal standard deviations are stable, indicating that the Seasonal indices may be additive model.

Table 4: Buys-Ballot table on the road traffic offences in Nigeria 


\begin{tabular}{|c|c|c|c|c|c|c|c|c|c|c|c|c|c|}
\hline $\bar{X}_{. j}$ & $\begin{array}{c}33152 . \\
7\end{array}$ & $\begin{array}{c}37868 . \\
8\end{array}$ & $\begin{array}{c}41744 . \\
5\end{array}$ & 36594 & $\begin{array}{c}39142 . \\
7\end{array}$ & $\begin{array}{c}35326 . \\
9\end{array}$ & 36601 & $\begin{array}{c}42528 . \\
5\end{array}$ & 35918 & $\begin{array}{c}36606 . \\
6\end{array}$ & $\begin{array}{c}44553 . \\
7\end{array}$ & $\begin{array}{c}34715 . \\
5\end{array}$ & $\begin{array}{c}37896.1 \\
7\end{array}$ \\
\hline$\sigma_{. j}^{2}$ & $\begin{array}{c}978044 \\
6\end{array}$ & $\begin{array}{c}158792 \\
463.4\end{array}$ & $\begin{array}{c}349300 \\
360.1\end{array}$ & $\begin{array}{c}19573 \\
9139\end{array}$ & $\begin{array}{c}214664 \\
3\end{array}$ & $\begin{array}{c}199927 \\
172.5\end{array}$ & $\begin{array}{c}22262 \\
5161 . \\
9\end{array}$ & $\begin{array}{c}437170 \\
557.5\end{array}$ & $\begin{array}{c}23340 \\
6043 . \\
7\end{array}$ & $\begin{array}{c}255221 \\
781.1\end{array}$ & $\begin{array}{c}896929 \\
395.0\end{array}$ & $\begin{array}{c}196479 \\
923.3\end{array}$ & \\
\hline
\end{tabular}

We want to check from Table 4, if the time series accepts additive model. The statistic in (27) is adopted. The null hypothesis that the series accepts additive model is accepted, if $\mathrm{W}$ is less than the tabulated value, for which $F_{\alpha(k-1)(N-k)}$ level of significance, or reject null hypothesis otherwise. When compared with the critical value (1.87), W is less than, suggesting the series accepts additive model.

From Table 4,

$$
\begin{aligned}
& Z_{i j}=\mid-0.03-0.02+0.02+0.05+0-0.03-0.01-0.04 \\
& Z_{i j}=|-2.05|=2.05 \\
& Z_{. .}=\frac{1}{s} \sum_{i=1}^{m} Z_{. j}=\frac{1}{12}(0.1864)=0.0155
\end{aligned}
$$$$
W=\frac{132-12}{(12-1)} \cdot \frac{11(0.1864-0.0155)^{2}}{(2.05-0.1864)^{2}}=1.0124
$$$$
F_{\alpha}, k-1, N-k
$$$$
F_{0.05}, 11,120=187
$$

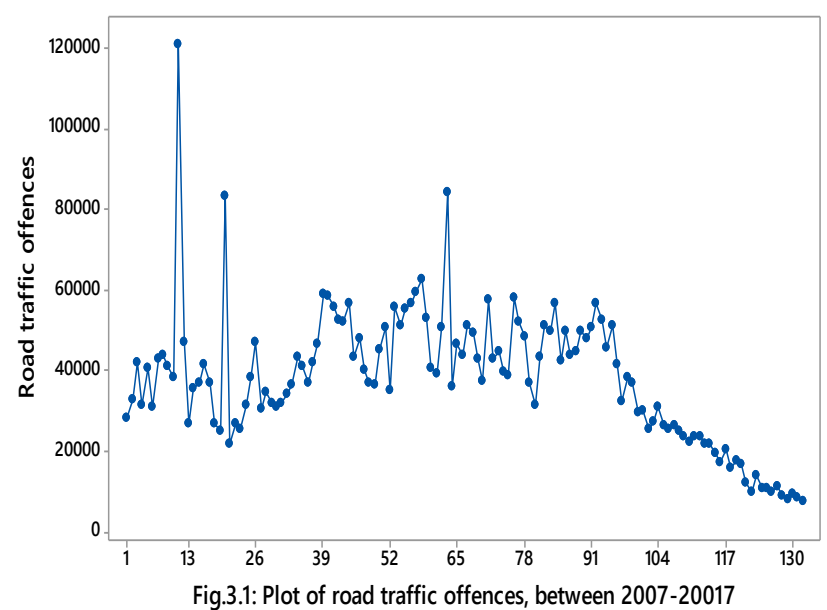

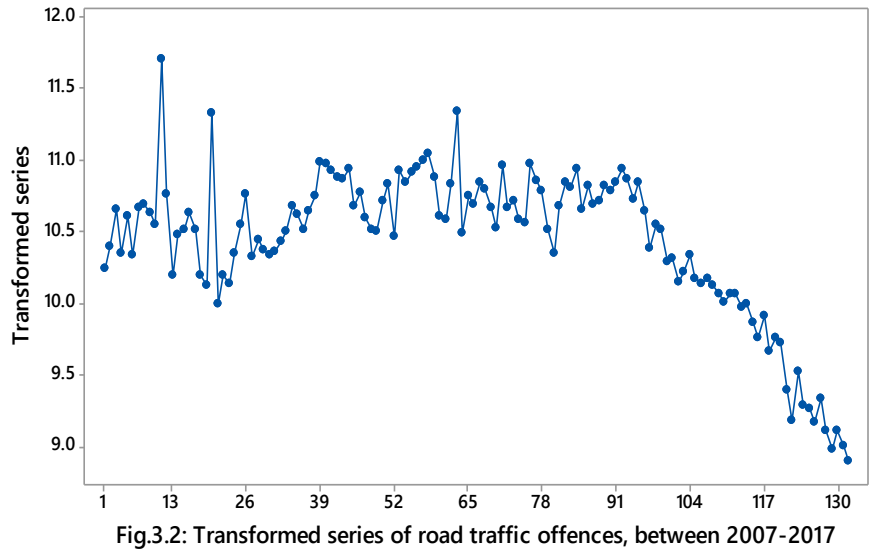

\section{CONCLUSION}

We have outlined the procedure for estimation of linear trend cycle and seasonal components that admits additive model. Also, we derived the periodic, seasonal and overall averages and variances with error terms and error variances. Results indicate that, 1$)$ the column variances $\left(\hat{\sigma}_{j}^{2}\right)$ of the BuysBallot table contain the trending series and seasonal indices 2) the suitable model that best describes the pattern of the study series obtained in the summary table (Table 4 ) is additive.

\section{REFERENCES}

[1] Chatfield, C. (2004). The analysis of time Series: An introduction. Chapman and Hall,/CRC Press, Boca Raton.

[2] Iwueze, I. S. \& Nwogu, E.C. (2014). Framework for choice of models and detection of seasonal effect in time series.Far East Journal of Theoretical Statistics 48(1), 45- 66

[3] Wei, W. W. S (1989). Time series analysis: Univariate and multivariate methods, Addison-Wesley publishing Company Inc, Redwood City

[4] Nwogu, E.C, Iwueze, I.S. Dozie, K.C.N. \& Mbachu, H.I (2019). Choice between mixed and multiplicative models in time series decomposition. International Journal of Statistics and Applications 9(5), 153-159

[5] Dozie (2020). Estimation of seasonal variances in descriptive time series analysis. Asian Journal of Advanced Research and Reports. 10(3): 37-47

[6] Dozie, K.C.N \& Uwaezuoke U.M (2020). Properties of Buys-Ballot estimates for mixed model in time series decomposition. Galore International Journal of Applied Sciences and Humanities 4(2), 35 - 40 
Appendix A: Buys-Ballot table of road traffic offences in Nigeria (2007-2017)

\begin{tabular}{|c|c|c|c|c|c|c|c|c|c|c|c|c|c|c|}
\hline Year & Jan. & Feb. & Mar. & Apr. & May & Jun. & Jul. & Aug. & Sept. & Oct. & Nov. & Dec. & $\bar{X}_{i}$ & $\sigma_{i}^{2}$ \\
\hline 2007 & 27905 & 32732 & 42104 & 31288 & 40529 & 30727 & 42742 & 43807 & 41146 & 38152 & 121049 & 47113 & 44941.2 & $\begin{array}{c}610818258 . \\
7\end{array}$ \\
\hline 2008 & 26613 & 35623 & 36655 & 41333 & 36827 & 26714 & 24782 & 83102 & 21793 & 26793 & 25334 & 31170 & 34728.3 & 268434131 \\
\hline 2009 & 38268 & 47134 & 30474 & 34365 & 31714 & 30673 & 31584 & 34008 & 36479 & 43294 & 40956 & 36710 & 36304.9 & 28174340.8 \\
\hline 2010 & 41683 & 46299 & 59036 & 58401 & 55681 & 52653 & 52107 & 56362 & 43392 & 47885 & 39863 & 36878 & 49186.7 & $\begin{array}{c}57679005.3 \\
3\end{array}$ \\
\hline 2011 & 36223 & 45036 & 50404 & 35008 & 55690 & 50946 & 55095 & 56681 & 59273 & 62365 & 53103 & 40482 & 50025.5 & 80211908.3 \\
\hline 2012 & 39294 & 50635 & 84203 & 35797 & 46285 & 43715 & 50989 & 49011 & 42607 & 37393 & 57381 & 42619 & 48327.4 & $\begin{array}{c}166439233 . \\
7\end{array}$ \\
\hline 2013 & 44724 & 39486 & 38661 & 58112 & 52004 & 48191 & 36777 & 31262 & 43449 & 51205 & 49543 & 56472 & 45823.8 & 67562322.7 \\
\hline 2014 & 42376 & 49697 & 43837 & 44665 & 49674 & 48038 & 50812 & 56405 & 52633 & 45569 & 51234 & 41617 & 48046.4 & 20260646.3 \\
\hline 2015 & 32164 & 38125 & 36687 & 29488 & 30114 & 25486 & 27264 & 30927 & 26211 & 25224 & 26201 & 24772 & 29388.6 & 19895997.2 \\
\hline 2016 & 23421 & 22098 & 23519 & 23348 & 21468 & 21871 & 19224 & 17262 & 20173 & 15726 & 17288 & 16709 & 20175.6 & 8142224.6 \\
\hline 2017 & 12009 & 9692 & 13609 & 10729 & 10584 & 9582 & 11242 & 8986 & 7943 & 9066 & 8139 & 7328 & 9909.1 & 3307375.2 \\
\hline $\bar{X}_{. j}$ & 33152.7 & 37868.8 & 41744.5 & 36594 & 39142.7 & 35326.9 & 36601 & 42528.5 & 35918 & 36606.6 & 44553.7 & 34715.5 & 37896.1 & \\
\hline$\sigma_{. j}^{2}$ & $\begin{array}{c}978044 \\
6\end{array}$ & $\begin{array}{c}158792 \\
463.4\end{array}$ & $\begin{array}{c}349300 \\
360.1\end{array}$ & $\begin{array}{l}19573 \\
9139.4\end{array}$ & $\begin{array}{c}214664 \\
393.8\end{array}$ & $\begin{array}{c}199927 \\
172.5\end{array}$ & $\begin{array}{l}22262 \\
5161.9\end{array}$ & $\begin{array}{c}437170 \\
557.5\end{array}$ & $\begin{array}{l}23340 \\
6043.7\end{array}$ & $\begin{array}{c}255221 \\
781.1\end{array}$ & $\begin{array}{c}896929 \\
395.0\end{array}$ & $\begin{array}{c}196479 \\
923.3\end{array}$ & & 3458064838 \\
\hline
\end{tabular}

Appendix B: Transformed series on road traffic offences in Nigeria (2007-2017)

\begin{tabular}{|c|c|c|c|c|c|c|c|c|c|c|c|c|c|c|}
\hline Year & Jan. & Feb. & Mar. & Apr. & May & Jun. & Jul. & Aug. & Sept. & Oct. & Nov. & Dec. & $\bar{X}_{i .}$ & $\sigma_{i}^{2}$ \\
\hline 2007 & 10.24 & 10.40 & 10.65 & 10.35 & 10.61 & 10.33 & 10.66 & 10.69 & 10.62 & 10.55 & 11.70 & 10.76 & 10.63 & 0.14 \\
\hline 2008 & 10.19 & 10.48 & 10.51 & 10.63 & 10.51 & 10.19 & 10.12 & 11.33 & 9.99 & 10.20 & 10.14 & 10.35 & 10.39 & 0.13 \\
\hline 2009 & 10.55 & 10.76 & 10.32 & 10.44 & 10.36 & 10.33 & 10.36 & 10.43 & 10.50 & 10.68 & 10.62 & 10.51 & 10.49 & 0.02 \\
\hline 2010 & 10.64 & 10.74 & 10.99 & 10.98 & 10.93 & 10.87 & 10.86 & 10.94 & 10.68 & 10.78 & 10.59 & 10.52 & 10.79 & 0.03 \\
\hline 2011 & 10.50 & 10.72 & 10.83 & 10.46 & 10.93 & 10.84 & 10.92 & 10.95 & 10.99 & 11.04 & 10.88 & 10.61 & 10.80 & 0.04 \\
\hline 2012 & 10.58 & 10.83 & 11.34 & 10.49 & 10.74 & 10.69 & 10.84 & 10.80 & 10.66 & 10.53 & 10.96 & 10.66 & 10.76 & 0.05 \\
\hline 2013 & 10.71 & 10.58 & 10.54 & 10.97 & 10.86 & 10.78 & 10.51 & 10.35 & 10.68 & 10.84 & 10.81 & 10.94 & 10.72 & 0.03 \\
\hline 2014 & 10.65 & 10.81 & 10.69 & 10.71 & 10.81 & 10.78 & 10.84 & 10.94 & 10.87 & 10.73 & 10.84 & 10.64 & 10.78 & 0.01 \\
\hline 2015 & 10.38 & 10.55 & 10.51 & 10.29 & 10.31 & 10.15 & 10.21 & 10.34 & 10.17 & 10.14 & 10.17 & 10.12 & 10.28 & 0.02 \\
\hline 2016 & 10.06 & 10.00 & 10.07 & 10.06 & 9.97 & 9.99 & 9.86 & 9.76 & 9.91 & 9.66 & 9.76 & 9.72 & 9.90 & 0.03 \\
\hline 2017 & 9.39 & 9.18 & 9.52 & 9.28 & 9.27 & 9.17 & 9.33 & 9.10 & 8.98 & 9.11 & 9.00 & 8.90 & 9.19 & \\
\hline $\bar{X}_{. j}$ & 10.35 & 10.46 & 10.54 & 10.42 & 10.48 & 10.37 & 10.41 & 10.51 & 10.37 & 10.39 & 10.50 & 10.34 & 10.43 & \\
\hline$\sigma_{. j}^{2}$ & 0.15 & 0.24 & 0.23 & 0.22 & 0.25 & 0.26 & 0.25 & 0.40 & 0.33 & 0.33 & 0.51 & 0.34 & & 0.01 \\
\hline
\end{tabular}

